\title{
PENGARUH KOMPENSASI DAN DIKLAT TERHADAP MOTIVASI KERJA MELALUI PENGEMBANGAN KARIR ASN DINAS PEKERJAAN UMUM DAN PENATAAN RUANG KABUPATEN BARRU
}

\author{
Herman Jaya $^{1}$, Ahmad Firman ${ }^{2}$, Muhammad Hidayat ${ }^{3}$ \\ herman.jaya69@gmail.com ${ }^{1}$, a_firman25@yahoo.com², hidayat2401@yahoo.com³ \\ STIE NOBEL INDONESIA MAKASSAR
}

\begin{abstract}
ABSTRAK
Motivasi memegang peranan yang sangat penting untuk mencapai tujuan organisasi. Motivasi kerja dipengaruhi oleh beberapa faktor antara lain kompensasi, pendidikan dan pelatihan (diklat), serta pengembangan karir. Masih rendahnya motivasi kerja pegawai Dinas Pekerjaan Umum dan Penataan Ruang (PUPR) Kabupaten Barru menyebabkan tujuan organisasi belum optimal. Penelitian bertujuan untuk menganalisis: 1) pengaruh langsung kompensasi dan diklat terhadap pengembangan karir pegawai Dinas PUPR Kabupaten Barru, 2) pengaruh langsung kompensasi dan diklat terhadap motivasi kerja pegawai Dinas PUPR Kabupaten Barru, 3) pengaruh tidak langsung kompensasi dan diklat terhadap motivasi kerja melalui pengembangan karir pegawai Dinas PUPR Kabupaten Barru. Penelitian ini menggunakan pendekatan kuantitatif dengan metode survey. Lokasi penelitian pada Dinas PUPR Kabupaten Barru yang dilaksanakan pada bulan Oktober sampai Nopember 2019. Sampel penelitian ditetapkan dengan teknik sampling jenuh yang mengambil seluruh populasi sebanyak 82 pegawai. Data yang terkumpul dianalisis dengan metode analisis jalur. Hasil penelitian menunjukkan: 1) kompensasi dan diklat secara langsung berpengaruh positif dan signifikan terhadap pengembangan karir pegawai Dinas PUPR Kabupaten Barru, 2) kompensasi dan diklat secara langsung berpengaruh positif dan signifikan terhadap motivasi kerja pegawai Dinas PUPR Kabupaten Barru, 3) kompensasi dan diklat secara tidak langsung berpengaruh positif terhadap motivasi kerja melalui pengembangan karir pegawai Dinas PUPR Kabupaten Barru.
\end{abstract}

Kata kunci: kompensasi, diklat, pengembangan karir dan motivasi kerja.

\begin{abstract}
The State Civil Apparatus is entrusted with three main tasks, namely providing services to the public, organizing general government, and carrying out development tasks. To carry out these three tasks the apparatus resource management plays a very important role. One function of human resource management is to increase employee motivation. Increased work motivation is influenced by several factors including compensation, education and training, and career development. The work motivation of the employees of the Public Works and Spatial Planning Office of Barru Regency has not been in line with expectations so that organizational goals do not achieve maximum results. The study aims to determine and analyze: 1) the direct effect of compensation and education and training on career development of the State Civil Service Office of Barru District Public Works and Spatial Planning, 2) the direct effect of compensation and training on work motivation of the State Civil Service Office of Barru District Public Works and Spatial Planning and 3) the indirect effect of compensation and education and training on work motivation through the career development of the State Civil Apparatus Office of Public Works and Spatial Planning of Barru Regency. The research approach is quantitative by using survey methods. The research was carried out at the Barru Regency Public Works and Spatial Planning Office for 2 (two) months, from October to November 2019. The study population was employees of the Barru Regency Public Works and Spatial Planning Office. Determination of the sample is done by saturation sampling technique (census), where the entire population of 82 people is used as a research sample. The data analysis technique used is path analysis. The results showed that: 1) compensation and education and training directly had a positive and significant effect on the career development of the State Civil Service Office of the Public Works and Spatial Planning in Barru District, 2) compensation and education and training directly had a positive and significant effect on the work motivation of the Apparatus State Civil Service of Public Works and Spatial Planning of Barru Regency, and 3) compensation and education and training indirectly have a positive and significant effect on work
\end{abstract}


motivation through career development of the State Civil Service Office of Public Works and Spatial Planning of Barru Regency.

Keywords: compensation, education and training, career development and work motivation.

\section{PENDAHULUAN}

Dalam rangka menciptakan tata kelola pemerintahan yang baik, upaya peningkatan sumber daya manusia aparatur perlu mendapatkan perhatian utama. Secara teori, kinerja sumber daya manusia berpengaruh terhadap motivasi kerja pegawai. Kinerja sumber daya manusia memegang peranan yang sangat penting dalam rangka pelayanan publik. Dilain sisi, kinerja sumber daya manusia membutuhkan adanya motivasi yang kuat dari setiap individu untuk meningkatkan potensi, keterampilan, keahlian dan kemampuan. Dengan adanya motivasi dan kemampuan yang dimiliki karyawan akan menciptakan suatu komitmen terhadap pekerjaan yang menjadi tanggung jawabnya sehingga pada akhirnya akan meningkatkan kinerja organisasi. Suatu organisasi atau perusahaan khususnya organisasi pemerintah tidak hanya mengharapkan para pegawainya mampu, cakap dan terampil dalam bekerja tetapi yang lebih penting adalah para pegawai mau bekerja dengan giat serta punya keinginan untuk menghasilkan pekerjaan yang maksimal. Menurut Mangkunegara (2010), motivasi adalah kondisi atau energi yang menggerakkan diri karyawan agar terarah dan tertuju untuk mencapai tujuan organisasi. Motivasi dapat pula menjadi pendorong, seseorang bersemangat untuk dapat bertindak atau berbuat dengan cara-cara tertentu yang menghasilkan karya optimal. Motivasi merupakan energi yang dapat menggerakkan pegawai lebih terarah untuk mencapai tujuan organisasi. Oleh karena itu untuk menghasilkan produktifitas kerja yang maksimal, peranan motivasi kerja menjadi sangat penting agar tujuan organisasi tercapai. Perilaku manusia dapat mempengaruhi motivasi kerja. Motivasi dapat pula menjadi pendorong seseorang bersemangat untuk dapat bertindak atau berbuat dengan cara-cara tertentu yang menghasilkan karya optimal. Indikator motivasi menurut Mangkunegara (2010) adalah: ruang kerja, sarana kerja, fasilitas kerja, perlindungan resiko, dan hubungan kerja. Unsur penting dalam motivasi adalah sistem kompensasi dan pengembangan kompetensi.

Dessler (2009), menyatakan bahwa kompensasi adalah semua bentuk pembayaran atau hadiah yang diberikan kepada karyawan dan muncul dari pekerjaan mereka. Kompensasi adalah pembayaran yang diberikan baik secara langsung maupun tidak langsung kepada pegawai sebagai balas jasa dari hasil pekerjaan yang telah dilaksanakan dengan skala waktu yang telah ditentukan oleh organisasi yang bersangkutan. Rahman dkk (2014), dalam penelitiannya menyimpulkan bahwa kompensasi dan kepemimpinan berpengaruh signifikan terhadap motivasi kerja karyawan. Sistem kompensasi yang memotivasi Aparatur Sipil Negara dewasa ini khususnya dalam lingkup Pemerintah Kabupaten Barru adalah kebijakan Tunjangan Kinerja yang lebih dikenal sebagai Tunjangan Perbaikan Penghasilan (TPP) disamping penggajian yang diatur secara nasional. Tunjangan Perbaikan Penghasilan diberikan sebagai penghargaan terhadap keberhasilan pelaksanaan reformasi birokrasi atas dasar penilaian kinerja pegawai. Indkator Kompensasi (Rivai, 2010) terdiri atas: Gaji, Insentif/Bonus, Tunjangan, Pujian, dan Promosi.

Disamping kompensasi, unsur lain dari motivasi adalah pengembangan kompetensi. Untuk mendorong motivasi karyawan dalam bekerja, diperlukan adanya hubungan kerja yang saling menguntungkan antara perusahaan dengan karyawan, 
Haryani dkk (2015). Hubungan kerja tersebut dapat melalui pengembangan kompetensi. Setiap Aparatur Sipil Negara (ASN) memiliki hak dan kesempatan untuk mengembangkan kompetensi, diantaranya melalui pendidikan dan pelatihan sebagaimana telah diatur dalam Undang-Undang Nomor 5 Tahun 2014 tentang Aparatur Sipil Negara. Wibowo (2012), berpendapat bahwa pendidikan dimaksudkan untuk mengembangkan atau meningkatkan kemampuan berpikir serta mengeluarkan gagasan-gagasan pada pegawai sehingga mereka dapat melaksanakan tugas dan tanggung jawab dengan sebaik-baiknya. Perbedaan antara pendidikan dan pelatihan terletak pada waktu pelaksanaan dan tujuannya. Pada pelaksanaan pendidikan, waktu dan materi lebih bersifat formal, sedangkan latihan lebih mengutamakan keterampilan bersifat teknis dan kurang formal dengan waktu yang lebih singkat. Setelah mengikuti pelatihan pegawai dapat menjalankan tugas dengan sebaik-baiknya. Pendidikan dan pelatihan merupakan salah satu kebutuhan pegawai yang dapat mempengaruhi kinerja. Dengan pendidikan dan diklat yang cukup sesuai komptensi bidang maka pegawai dapat meningkatkan pengetahuan dan keterampilannya. Indikator pelaksanaan diklat menurut Sofyandi (2008), yaitu: Isi diklat, metode diklat, keterampilan instruktur, lama waktu diklat, dan fasilitas diklat.

Hal lain yang dapat memotivasi seorang pegawai dalam bekerja adalah adanya pola pengembangan karir yang jelas. Pengertian karir menurut Soetjipto dalam Simamora (2009), adalah bagian dari perjalanan hidup seseorang bahkan bagi sebagian orang merupakan suatu tujuan hidup. Oleh sebab itu karir dapat diartikan sebagai serangkaian aktivitas dari pekerjaan yang berkelanjutan dan melibatkan pilihan dari berbagai kesempatan yang terjadi akibat interaksi individu dengan organisasi dan lingkungan sosialnya. Pengembangan karir di instansi pemerintah adalah suatu keadaan dalam rangkaian atau tahapan pengembangan pekerjaan maupun jabatan dari yang terendah sampai tingkatan tertinggi yang bisa dicapai seorang ASN sejak diangkat menjadi pegawai. Untuk mewujudkan rencana tersebut seyogyanya seorang pegawai perlu menyiapkan langkah-langkah antara lain atas kemauan sendiri, atas inisiatif organisasi maupun gabungan dari keduanya.Indikator pengembangan karir menurut Rivai (2010), adalah: promosi, mutasi, perlakuan adil, pelatihan, dan studi lanjut.

Fenomena rendahnya motivasi, pengembangan karir yang belum optimal, kompensasi yang masih kurang dan diklat yang belum sesuai harapan menyebabkan adanya ASN dalam melaksanakan tugasnya masih menunda-nunda pekerjaan, padahal harus segera diselesaikan sehingga proses pekerjaan menjadi sering terjadi keterlambatan bahkan dapat mengakibatkan ASN merasa dirugikan akibat keterlambatan tersebut. Selanjutanya, kurangnya tanggung jawab dalam diri ASN terhadap tugas dan kewajiban karena adanya ASN yang telah cukup lama pada salah satu unit tertentu sehingga menganggap enteng pekerjaan dan merasa lebih tahu dari yang lain menyebabkan kualitas hasil kerja dicapai menjadi tidak memadai. Disamping hal tersebut, rendahnya hasil kerja yang dicapai ASN karena adanya ASN yang belum memahami peran dan fungsinya karena keterbatasan pengetahuan dan kemampuan karena penempatan ASN yang tidak sesuai dengan latar belakang yang dimiliki, kemudian rendahnya inisiatif ASN dalam melaksanakan tugasnya karena tidak diberdayakannya ASN yang memiliki kapasitas yang sesuai dengan bidang tugasnya.

Berdasarkan uraian tersebut di atas, pengaruh kompensasi dan diklat terhadap pengembangan karir dan motivasi kerja dapat digambarkan menjadi kerangka konseptual sebagai berikut: 


\section{AkMen}

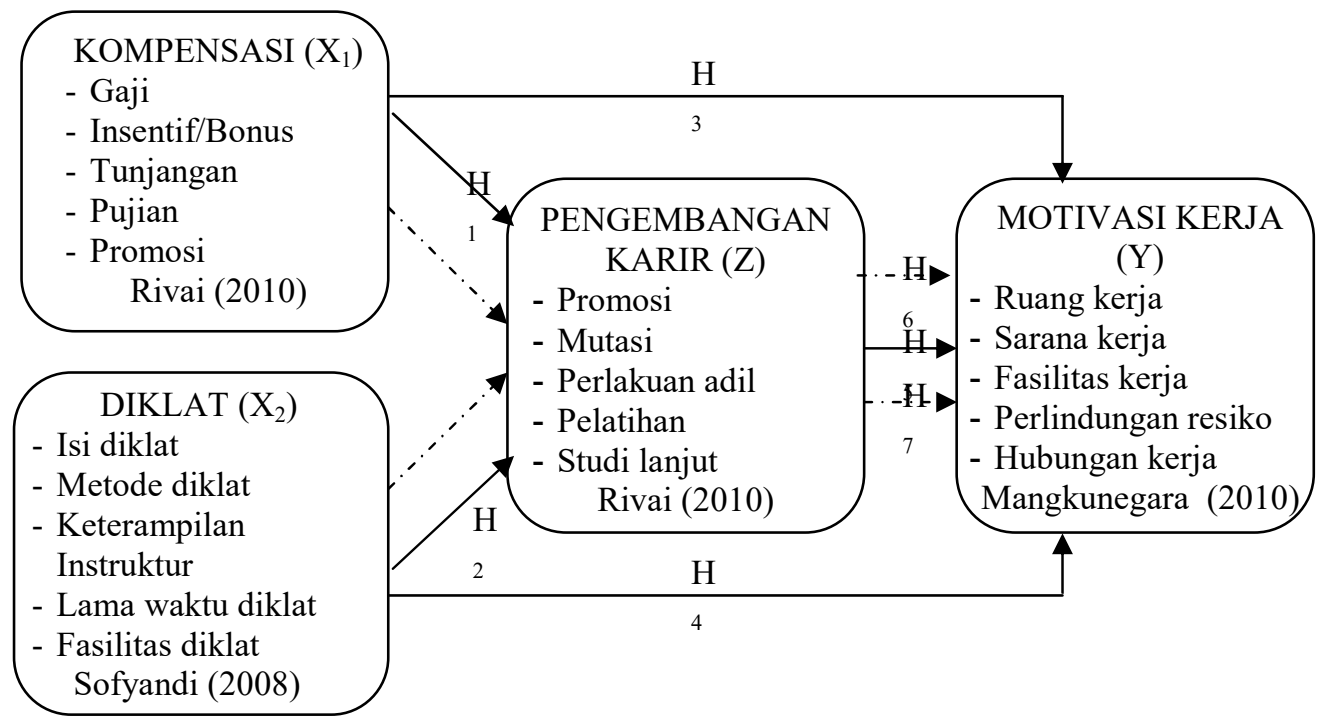

\section{Keterangan $: \cdots \cdots \cdots \cdots \cdots$ arah hubungan parsial \\ arah hubungan intervening \\ Gambar 1 Kerangka Konseptual Penelitian}

Dari kerangka konseptual sebagaimana pada gambar 1, hubungan kausal antara kompensasi, diklat, pengembangan karir dan motivasi kerja dapat dirumuskan dalam hipotesis penelitian sebagai berikut;

1. Kompensasi dan diklat berpengaruh positif dan signifikan terhadap pengembangan karir ASN Dinas PUPR Kabupaten Barru.

2. Kompensasi dan diklat berpengaruh positif dan signifikan terhadap motivasi kerja ASN Dinas PUPR Kabupaten Barru.

3. Kompensasi dan diklat berpengaruh positif dan signifikan terhadap motivasi kerja melalui pengembangan karir ASN Dinas PUPR Kabupaten Barru.

\section{METODE PENELITIAN}

Pendekatan penelitian ini menggunakan penelitian survey yang mengambil sampel dari satu populasi dan menggunakan kuisioner sebagai alat pengumpul data yang pokok (Singarimbun, 2008). Populasi dalam penelitian ini adalah pegawai Dinas Pekerjaan Umum dan Penataan Ruang Kabupaten Barru yang berstatus Aparat Sipil Negara (ASN) sebanyak 82 orang.dan seluruh populasi ini yang digunakan sebagai sampel penelitian. Untuk mendapatkan data yang berkualitas maka data terlebih dahulu diuji melalui uji validitas dan realibilitas yang selanjutnya dilakukan analisis data melalui analisis jalur (path analysis) dengan kerangka jalur sebagai berikut:

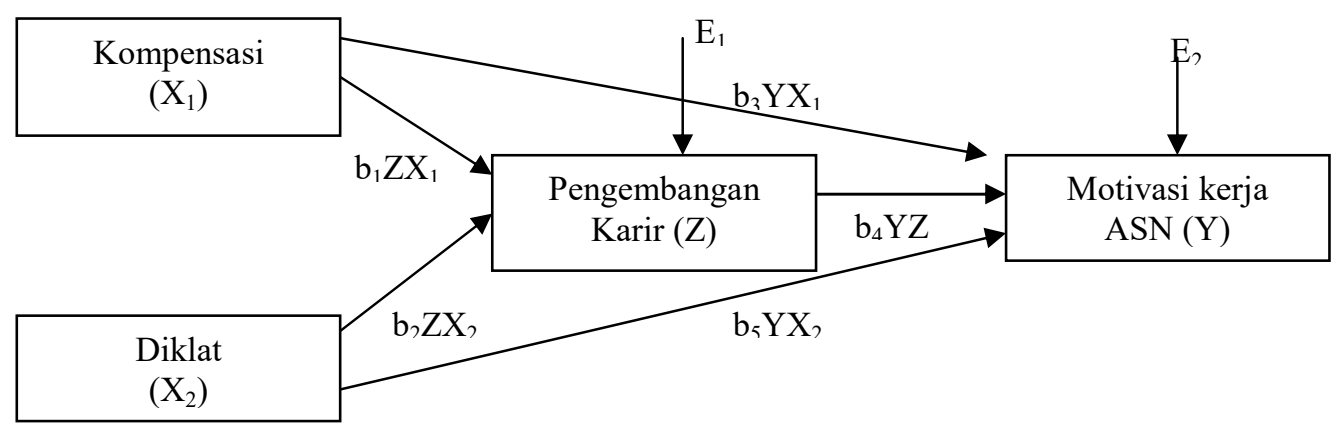


Gambar 2 Penggambaran Asumsi Analisis Jalur

Persamaan struktural model regresi sebagai berikut:

a. Persamaan Substruktur Pertama

$$
Z=b_{1} Z X_{1}+b_{2} Z X_{2}+E_{1}
$$

b. Persamaan Substruktur Kedua

$$
\mathbf{Y}=\mathrm{b}_{3} \mathbf{Y X} \mathbf{X}_{1}+\mathrm{b}_{4} \mathbf{Y Z}+\mathrm{b}_{5} \mathbf{Y X _ { 2 }}+\mathrm{E}_{2}
$$

Pengaruh secara parsial dilakukan dengan uji t dan pengaruh simultan dilakukan dengan menggunakan uji f, selanjutnya uji koefisien determinasi untuk menghitung besarnya pengaruh seluruh variabel bebas secara simultan terhadap variabel terikat.

\section{HASIL PENELITIAN DAN PEMBAHASAN}

\section{Hasil Penelitian}

\section{Uji Validitas dan Reliabilitas}

Sebelum data dianalisis terlebih dahulu dilakukan uji validitas dan realibilitas untuk mengetahui kelayakan instrumen yang digunakan dalam penelitian. Item kuisioner penelitian dinyatakan valid jika $\mathrm{r}$ hitung $>\mathrm{r}$ tabel dan realibel jika hasil koefisien cronbach alpha $>0,60$. Adapun hasil uji uji validitas dan realibilitas masingmasing variabel penelitian dapat dilihat pada tabel berikut ini.

Tabel 1 Hasil Uji Validitas dan Reliabilitas Variabel Kompensasi

\begin{tabular}{c|c|c|c}
\hline Variabel & r hitung & $\mathrm{r}$ tabel & Kesimpulan \\
\hline $\mathrm{X}_{1.1}$ & 0,676 & 0,217 & Valid \\
\hline $\mathrm{X}_{1.2}$ & 0,729 & 0,217 & Valid \\
\hline $\mathrm{X}_{1.3}$ & 0,738 & 0,217 & Valid \\
\hline $\mathrm{X}_{1.4}$ & 0,650 & 0,217 & Valid \\
\hline $\mathrm{X}_{1.5}$ & 0,626 & 0,217 & Valid \\
\hline \multicolumn{4}{|c}{ Koefisien Cronbach Alpha $=0,863$} \\
\hline
\end{tabular}

\section{Sumber: Data SPSS Diolah, 2019}

Berdasarkan tabel 1 semua item variabel kompensasi dinyatakan valid dan reliabel yang berarti bahwa hasil kuisioner dari item ini dapat digunakan untuk analisis selanjutnya.

Tabel 2 Hasil Uji Validitas dan Reliabilitas Variabel Diklat

\begin{tabular}{c|c|c|c}
\hline Item & r hitung & r tabel & Kesimpulan \\
\hline $\mathrm{X}_{2.1}$ & 0,729 & 0,217 & Valid \\
\hline $\mathrm{X}_{2.2}$ & 0,702 & 0,217 & Valid \\
\hline $\mathrm{X}_{2.3}$ & 0,773 & 0,217 & Valid \\
\hline $\mathrm{X}_{2.4}$ & 0,644 & 0,217 & Valid \\
\hline $\mathrm{X}_{2.5}$ & 0,708 & 0,217 & Valid \\
\hline
\end{tabular}

Koefisien Cronbach Alpha $=0,879$

\section{Sumber: Data SPSS Diolah, 2019}

Sebagaimana hasil pada tabel 2 bahwa semua item pertanyaan pada variabel pendidikan dan diklat dinyatakan valid dan reliabel sehingga data hasil kuisioner pada variabel ini dapat dipergunakan untuk analisis selanjutnya.

Tabel 3 Hasil Uji Validitas dan Reliabilitas Variabel Pengembangan Karir

\begin{tabular}{l|c|c|c} 
Item & r hitung & r tabel & Kesimpulan \\
\hline
\end{tabular}




\begin{tabular}{c|c|c|c}
\hline$Z_{1}$ & 0,633 & 0,217 & Valid \\
\hline$Z_{2}$ & 0,670 & 0,217 & Valid \\
\hline$Z_{3}$ & 0,639 & 0,217 & Valid \\
\hline$Z_{.4}$ & 0,595 & 0,217 & Valid \\
\hline$Z_{.5}$ & 0,561 & 0,217 & Valid \\
\hline \multicolumn{4}{|c}{ Koefisien Cronbach Alpha $=0,825$} \\
\hline
\end{tabular}

Sumber: Data SPSS Diolah, 2019

Data yang ditampilkan pada tabel 3 bahwa semua item pertanyaan pada variabel pengembangan karir menghasilkan nilai $r$ hitung $>r$ tabel, demikian pula dengan nilai cronbach alpha $>0,60$ sehingga dinyatakan valid dan reliabel.

Tabel 4 Hasil Uji Validitas dan Reliabilitas Variabel Motivasi Kerja

\begin{tabular}{c|c|c|c}
\hline Item & $\mathrm{r}$ hitung & $\mathrm{r}$ tabel & Kesimpulan \\
\hline $\mathrm{Y}_{.1}$ & 0,806 & 0,217 & Valid \\
\hline $\mathrm{Y}_{.2}$ & 0,789 & 0,217 & Valid \\
\hline $\mathrm{Y}_{.3}$ & 0,691 & 0,217 & Valid \\
\hline$Y_{.4}$ & 0,784 & 0,217 & Valid \\
\hline$Y_{.5}$ & 0,741 & 0,217 & Valid \\
\hline \multicolumn{4}{|c}{ Koefisien Cronbach Alpha $=0,902$ (Reliabel) }
\end{tabular}

\section{Sumber: Data SPSS Diolah, 2019}

Pada tabel 4 juga menunjukkan semua konstruk pertanyaan pada variabel motivasi kerja dinyatakan valid dan reliabel oleh karena nilai $r$ hitung $>\mathrm{r}$ tabel, demikian pula nilai cronbach alpha $>0,60$.

\section{Analisis Jalur (Path Analysis) Substruktur Pertama}

Untuk mengetahui kelayakan model regresi dan pengaruh simultan persamaan substruktur pertama dilakukan dengan uji $\mathrm{F}$ (Anova).

Tabel 5 Hasil Uji F Sub Struktur Pertama

\begin{tabular}{l|l|r|r|r|r|r}
\hline \multicolumn{7}{|c|}{ ANOVA $^{\mathrm{a}}$} \\
\hline \multirow{2}{*}{ Model } & $\begin{array}{c}\text { Sum of } \\
\text { Squares }\end{array}$ & \multicolumn{1}{c|}{ df } & $\begin{array}{c}\text { Mean } \\
\text { Square }\end{array}$ & \multicolumn{1}{c}{ F } & \multicolumn{1}{c}{ Sig. } \\
\hline 1 & $\begin{array}{l}\text { Regressio } \\
\text { n }\end{array}$ & 18.611 & 2 & 9.306 & 215.654 & $.000^{\mathrm{b}}$ \\
\cline { 2 - 7 } & Residual & 3.409 & 79 & .043 & & \\
\cline { 2 - 8 } & Total & 22.020 & 81 & & & \\
\hline
\end{tabular}

a. Dependent Variable: Pengembangan Karir

b. Predictors: (Constant), Diklat, Kompensasi

\section{Sumber : Data SPSS Diolah, 2019}

Nilai (Sig.) 0,000<0,005 berarti koefisien regresi predictor $\left(\mathrm{b}_{1}, \mathrm{~b}_{2}\right)$ signifikan dan model regresi dinyatakan layak. Nilai $\mathrm{F}_{\text {hitung }}=215.654>\mathrm{F}$ tabel $=3,11$ menunjukkan variabel kompensasi (X1) dan diklat (X2) secara simultan berpengaruh terhadap pengembangan karir $(Z)$. 
Besarnya pengaruh simultan variabel X1 dan X2 terhadap variabel Z dapat dilihat pada tabel 6.

\section{Tabel 6 Koefisien Determinasi Sub Struktur Pertama} Model Summary ${ }^{\mathrm{b}}$

\begin{tabular}{l|c|r|r|r|r}
\hline Model & R & R Square & $\begin{array}{c}\text { Adjusted R } \\
\text { Square }\end{array}$ & $\begin{array}{c}\text { Std. Error of } \\
\text { the Estimate }\end{array}$ & $\begin{array}{c}\text { Durbin- } \\
\text { Watson }\end{array}$ \\
\hline 1 & $.919^{\mathrm{a}}$ & .845 & .841 & .20773 & 2.060 \\
\hline
\end{tabular}

a. Predictors: (Constant), Diklat, Kompensasi

b. Dependent Variable: Pengembangan Karir

\section{Sumber : Data SPSS Diolah, 2019}

Pada tabel di atas, nilai $\mathrm{R}$ Square sebesar 0,845, yang menunjukkan bahwa secara simultan (serempak) kompensasi dan diklat berpengaruh terhadap pengembangan karir dengan nilai 0,845 atau 84,5\%, sedangkan sisanya sebesar $\quad(1-0,845)=0,155$ atau $15,5 \%$ dipengaruhi oleh variabel lain yang tidak diteliti (e1).

Pengaruh langsung variabel X1 dan X2 terhadap variabel Z sebagai berikut:

Tabel 7 Hasil Uji t Sub Struktur Pertama

\begin{tabular}{|c|c|c|c|c|c|c|c|c|}
\hline \multicolumn{9}{|c|}{ Coefficients $^{\mathrm{a}}$} \\
\hline & & \multicolumn{2}{|c|}{$\begin{array}{l}\text { Unstandardize } \\
\text { d Coefficients }\end{array}$} & \multirow{2}{*}{$\begin{array}{c}\begin{array}{c}\text { Standardize } \\
\mathrm{d} \\
\text { Coefficient } \\
\mathrm{s}\end{array} \\
\text { Beta }\end{array}$} & \multirow[b]{2}{*}{$\mathrm{t}$} & \multirow[b]{2}{*}{ Sig. } & \multicolumn{2}{|c|}{$\begin{array}{c}\text { Collinearity } \\
\text { Statistics }\end{array}$} \\
\hline \multicolumn{2}{|c|}{ Model } & $\mathrm{B}$ & \begin{tabular}{|l} 
Std. \\
Error
\end{tabular} & & & & $\begin{array}{c}\text { Toleran } \\
\text { ce }\end{array}$ & VIF \\
\hline \multirow[t]{3}{*}{1} & (Constant) & .327 & .164 & & 1.991 & .050 & & \\
\hline & $\begin{array}{l}\text { Kompensasi } \\
\text { (X1) }\end{array}$ & .419 & .119 & .444 & 3.522 & .001 & .123 & 8.102 \\
\hline & Diklat (X2) & .456 & .117 & .491 & 3.893 & .000 & .123 & 8.102 \\
\hline
\end{tabular}

a. Dependent Variable: Pengembangan Karir

\section{Sumber : Data SPSS Diolah, 2019}

$\mathrm{X} 1: \mathrm{t}_{\text {hitung }}=3,552>\mathrm{t}$ tabel 1.664; (Sig.) $=0,001<$ alpha $=0,05$ (Ho ditolak), sehingga dapat disimpulkan bahwa kompensasi (X1) berpengaruh secara langsung terhadap pengembangan karir $(Z)$ dengan nilai pengaruh sebesar 0,444 atau $44,4 \%$.

$\mathrm{X} 2: \mathrm{t}_{\text {hitung }}=3,893>\mathrm{t}$ tabel 1.664 ; (Sig.) $=0,000<$ alpha $=0,05$ (Ho ditolak), sehingga dapat disimpulkan bahwa diklat (X2) berpengaruh secara langsung terhadap pengembangan karir $(Z)$ dengan nilai pengaruh sebesar 0,491 atau $49,1 \%$.

Hasil analisis jalur substruktur pertama digambarkan sebagai berikut: 


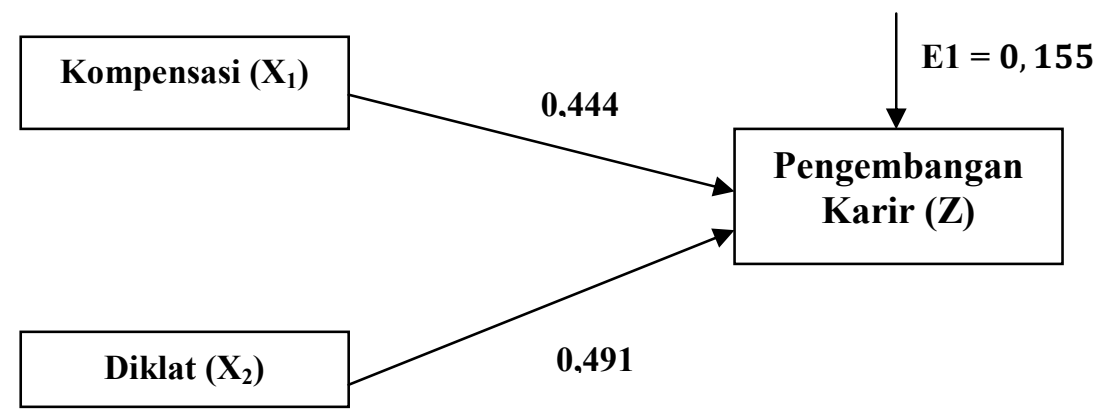

Gambar 3 Hasil Estimasi Jalur Sub Struktur Pertama

Berdasarkan hasil estimasi jalur sub struktur pertama sebagaimana pada gambar 3 tersebut di atas, persamaan strukturalnya adalah:

$$
\mathrm{Z}=0,444 X 1+0,491 \times 2+0,155 \mathrm{E}_{1}
$$

\section{Analisis Jalur (Path Analysis) Sub Struktur Kedua}

Uji kelayakan model regresi dan pengaruh simultan persamaan substruktur kedua dapat dilihat pada tabel 8 .

Tabel 8 Hasil Uji F Sub Struktur Kedua ANOVA ${ }^{\mathrm{a}}$

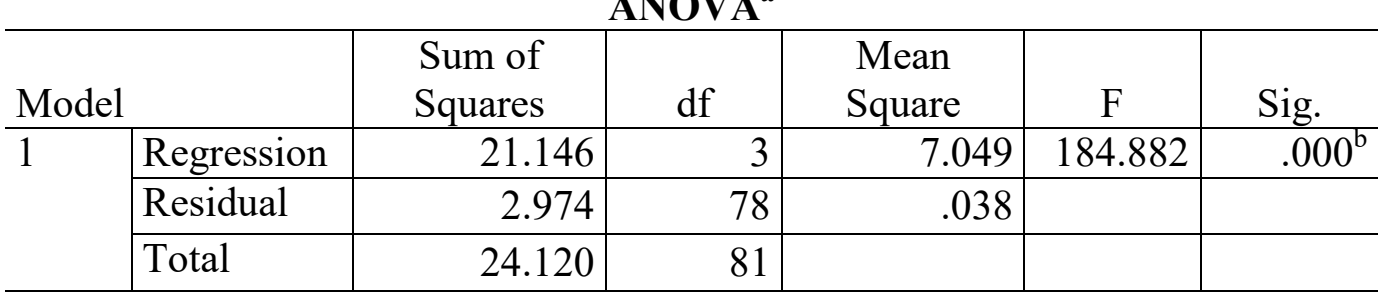

a. Dependent Variable: Motivasi Kerja

b. Predictors: (Constant), Pengembangan Karir, Kompensasi, Diklat

Sumber : Data Diolah, 2019

Nilai (Sig.) $0,000<0,005$ berarti koefisien regresi predictor $\left(b_{3}, b_{4}, b_{5}\right)$ signifikan dan model regresi dinyatakan layak. Nilai $\mathrm{F}_{\text {hitung }}=184.882>\mathrm{F}$ tabel $=2,72$ menunjukkan variabel kompensasi (X1), diklat (X2), dan pengembangan karir (Z) secara serempak (bersama-sama) berpengaruh terhadap variabel motivasi kerja (Y).

Besarnya pengaruh serempak dari ketiga variabel ini dapat dilihat dari koefisien determinasinya berikut ini:

\section{Tabel 9 Koefisien Determinasi Sub Struktur Kedua} Model Summary ${ }^{b}$

\begin{tabular}{l|c|c|r|r|r}
\hline Model & $\mathrm{R}$ & $\begin{array}{c}\mathrm{R} \\
\text { Square }\end{array}$ & $\begin{array}{c}\text { Adjusted R } \\
\text { Square }\end{array}$ & $\begin{array}{c}\text { Std. Error of the } \\
\text { Estimate }\end{array}$ & $\begin{array}{c}\text { Durbin- } \\
\text { Watson }\end{array}$ \\
\hline 1 & $.936^{\mathrm{a}}$ & .877 & .872 & .19526 & 2.340 \\
\hline
\end{tabular}

a. Predictors: (Constant), Pengembangan Karir, Kompensasi, Diklat

b. Dependent Variable: Motivasi Kerja

\section{Sumber : Data Diolah, 2019}

Dari Tabel 9 di atas, nilai koefisien determinasi (R Square) adalah sebesar 0,877 atau sama dengan $87,7 \%$ mengandung arti bahwa variabel kompensasi (X1), diklat 
(X2), dan pengembangan karir (Z) secara simultan berpengaruh terhadap motivasi kerja (Y) sebesar $87,7 \%$, sedangkan selebihnya sebesar $(1-0,877)=0,123$ atau $12,3 \%$ dipengaruhi oleh variabel lain diluar variabel yang diteliti atau disebut juga variabel error (e2).

Pengaruh langsung variabel X1, X2, dan Z terhadap variabel Y sebagai berikut:

Tabel 10 Hasil Uji t Sub Struktur Kedua

\section{Coefficients $^{\mathrm{a}}$}

\begin{tabular}{|c|c|c|c|c|c|c|c|c|}
\hline & & \multicolumn{2}{|c|}{$\begin{array}{l}\text { Unstandardiz } \\
\text { ed } \\
\text { Coefficients }\end{array}$} & \multirow{2}{*}{$\begin{array}{c}\text { Standardiz } \\
\text { ed } \\
\text { Coefficient } \\
\text { s }\end{array}$} & \multirow[b]{2}{*}{$\mathrm{t}$} & \multirow[b]{2}{*}{ Sig. } & \multicolumn{2}{|c|}{$\begin{array}{l}\text { Collinearity } \\
\text { Statistics }\end{array}$} \\
\hline \multicolumn{2}{|c|}{ Model } & B & $\begin{array}{l}\text { Std. } \\
\text { Error }\end{array}$ & & & & $\begin{array}{l}\text { Toleran } \\
\text { ce }\end{array}$ & VIF \\
\hline \multirow[t]{4}{*}{1} & (Constant) & .133 & .158 & & .843 & .402 & & \\
\hline & Kompensasi & .340 & .120 & .344 & 2.824 & .006 & .107 & 9.374 \\
\hline & Diklat & .345 & .120 & .354 & 2.868 & .005 & .104 & 9.656 \\
\hline & $\begin{array}{l}\text { Pengembanga } \\
\text { n Karir }\end{array}$ & .277 & .106 & .265 & 2.623 & .010 & .155 & 6.460 \\
\hline
\end{tabular}

a. Dependent Variable: Motivasi Kerja

Sumber : Data SPSS Diolah, 2019

$\mathrm{X} 1: \mathrm{t}_{\text {hitung }}=2,824>\mathrm{t}$ tabel 1.664 ; (Sig.) $=0,006<$ alpha $=0,05$ (Ho ditolak), dapat disimpulkan bahwa kompensasi (X1) berpengaruh secara langsung dan signifikan terhadap motivasi kerja (Y) dengan nilai pengaruh sebesar 0,344 atau $34,4 \%$

$\mathrm{X} 2: \mathrm{t}_{\text {hitung }}=2,868>\mathrm{t}_{\text {tabel }}$ 1.664; (Sig.) $=0,000<$ alpha $=0,05$ (Ho ditolak), hal ini berarti diklat (X2) berpengaruh secara langsung dan signifikan terhadap motivasi kerja (Y) dengan nilai pengaruh sebesar 0,354 atau $35,4 \%$.

$\mathrm{Z}: \mathrm{t}_{\text {hitung }}=2,623>\mathrm{t}_{\text {tabel }} 1.664$; (Sig.) $=0,010<$ alpha $=0,05$ (Ho ditolak), dapat disimpulkan bahwa pengembangan karir $(\mathrm{Z})$ berpengaruh secara langsung dan signifikan terhadap motivasi kerja (Y) dengan nilai pengaruh sebesar 0,265 atau $26,5 \%$.

Analisis jalur substruktur kedua digambarkan sebagai berikut: 


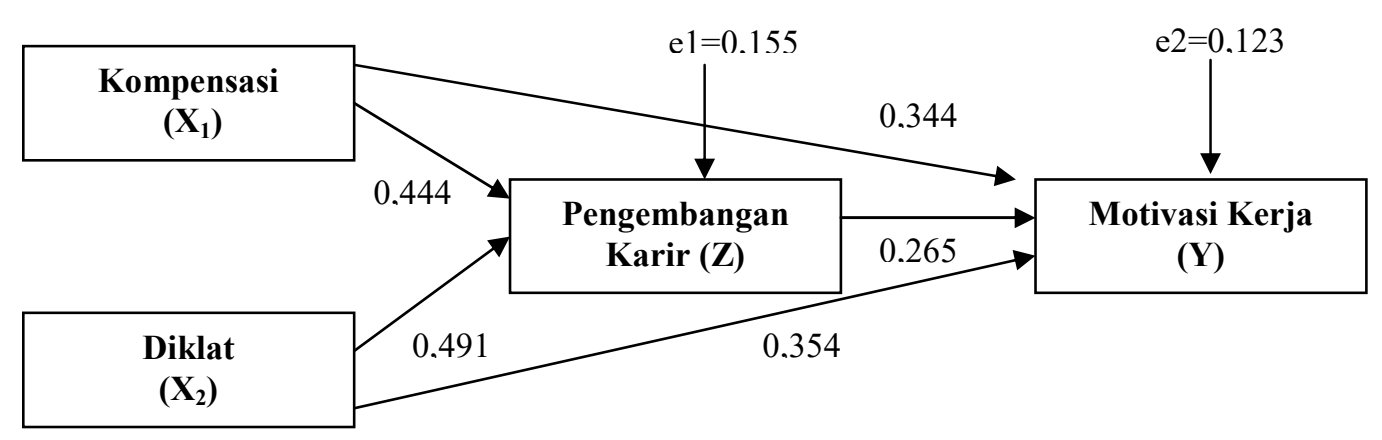

Gambar 4 Hasil Analisis Jalur Sub Struktur Kedua

Hasil estimasi jalur sub struktur kedua sebagaimana pada gambar 4 tersebut di atas, persamaan strukturalnya adalah:

$$
Y=0,344 X 1+0,265 Z+0,354 X 2+0,123 E 2
$$

Dari hasil estimasi jalur persamaan substruktur pertama dan kedua, besarnya pengaruh tidak langsung variabel $\mathrm{X} 1$ dan $\mathrm{X} 2$ terhadap variabel $\mathrm{Y}$ melalui variabel $\mathrm{Z}$ dapat dihitung sebagai berikut:

a. $X_{1} \rightarrow Z \rightarrow Y=\left(b_{1} \times b_{4}\right)=(0,444 \times 0,265)=0,117$, ini berarti bahwa pengaruh tidak langsung kompensasi terhadap motivasi kerja melalui pengembangan karir adalah sebesar 0,117 atau $11.7 \%$.

b. $\mathrm{X} 2 \rightarrow \mathrm{Z} \rightarrow \mathrm{Y}=(\mathrm{b} 2 \times \mathrm{b} 4)=(0,491 \times 0,265)=0,130$, yang berarti pengaruh tidak langsung diklat (X2) terhadap motivasi kerja (Y) melalui pengembangan karir (Z) adalah sebesar 0,130 atau $13.0 \%$.

Selanjutnya pengaruh total (total effect) variabel X1 dan X2 terhadap Y melalui $\mathrm{Z}$ adalah sebagai berikut:

a. Total Effect $\left(\mathrm{X}_{1}\right)=$ pengaruh langsung + pengaruh tidak langsung

$$
\begin{aligned}
& =0,344+0,117 \\
& =0,461
\end{aligned}
$$

b. Total Effect $(\mathrm{X} 2)=$ pengaruh langsung + pengaruh tidak langsung

$=0,354+0,130$

$=0,484$

Hasil seluruh koefisien jalur dari hubungan kausalitas yang ada ditampilkan pada tabel berikut ini:

Tabel 11 Rangkuman Hasil Pengaruh Berdasarkan Koefisien Jalur

\begin{tabular}{l|c|c|c|c}
\hline \multirow{2}{*}{ Pengaruh Variabel } & \multirow{2}{*}{$\begin{array}{c}\text { Koefisien } \\
\text { Jalur }\end{array}$} & Langsung & $\begin{array}{c}\text { Tidak } \\
\text { Langsung }\end{array}$ & Total \\
\cline { 3 - 5 } & $\mathrm{b}_{1} \mathrm{ZX}_{1}$ & 0,444 & - & - \\
\hline $\mathrm{X} 1 \rightarrow \mathrm{Z} 2 \rightarrow \mathrm{Z}$ & $\mathrm{b}_{2} \mathrm{ZX}_{2}$ & 0,491 & - & - \\
\hline $\mathrm{X} 1 \rightarrow \mathrm{Y}$ & $\mathrm{b}_{3} \mathrm{YX}_{1}$ & 0,344 & 0,117 & 0,461 \\
\hline $\mathrm{X} 2 \rightarrow \mathrm{Y}$ & $\mathrm{b}_{5} \mathrm{YX}_{2}$ & 0,354 & 0,130 & 0,484 \\
\hline $\mathrm{Z} \rightarrow \mathrm{Y}$ & $\mathrm{b}_{4} \mathrm{YZ}$ & 0,265 & - & - \\
\hline $\mathrm{X} 1, \mathrm{X} 2 \rightarrow \mathrm{Y}$ & - & - & - & 0,845 \\
\hline
\end{tabular}




\begin{tabular}{l|l|l|l|l}
\hline $\mathrm{X} 1, \mathrm{X} 2, \mathrm{Z} \rightarrow \mathrm{Y}$ & - & - & - & 0,877 \\
\hline $\mathrm{E} 1$ & - & - & - & 0,155 \\
\hline $\mathrm{E} 2$ & - & - & - & 0,123 \\
\hline
\end{tabular}

Sumber : Data Diolah, 2019

\section{Pembahasan Hasil Penelitian}

Pada uji hipotesis diperoleh hasil bahwa kompensasi dan diklat berpengaruh positif dan signifikan terhadap pengembangan karir. Pendapat yang sama dikemukakan oleh Haryani, dkk (2015) yang menyimpulkan bahwa kompensasi secara signifikan berpengaruh terhadap motivasi kerja dan kinerja karyawan. Hipotesis tersebut didukung oleh hasil kuisioner dimana indikator kompensasi yaitu gaji, insentif/bonus, tunjangan, pujian, dan promosi yang didistribusikan dalam penyataan-pernyataan dalam kuisioner dengan rata-rata jawaban sangat tinggi yaitu 3,84 . Hasil ini juga sejalan dengan kondisi yang terjadi di lapangan melalui wawancara yang telah dilakukan dapat disimpulan bahwa kompensasi yang baik akan memberikan dorongan untuk melakukan pekerjaan dengan lebih baik yang pada akhirnya akan berpengaruh terhadap pengembangan karir. Jawaban responden terhadap pertanyaan pada variabel diklat dengan nilai rata-rata 3,86. Karir ASN sangat dipengaruhi oleh pendidikan dan pelatihan yang telah diikuti, baik berupa diklat fungsional maupun diklat struktural. Seorang ASN kurang memperoleh kesempatan promosi jabatan jika tidak memiliki diklat tertentu, begitu pula dengan pendidikan formal.

Hasil penelitian menunjukan bahwa kompensasi dan diklat secara langsung berpengaruh positif dan signifikan terhadap motivasi kerja. Dalam penelitian sebelumnya Azis (2014), menyimpulkan bahwa kompensasi dan kepemimpinan berpengaruh signifikan terhadap motivasi kerja karyawan. Data hasil kuesioner menunjukkan tingkat rata-rata jawaban responden sangat tingg yaitu sebesar 3,70. Sistem penggajian yang sudah mulai ada perbaikan-perbaikan berkorelasi positif terhadap peningkatan motivasi kerja ASN walaupun pola penggajian tersebut masih diharapkan adanya peningkatan terhadap kompensasi. Semakin baik sistem kompensasi akan meningkatkan pula motivasi kerja ASN. Akan tetapi sistem penggajian yang sama pada jenjang kepangkatan, golongan dan ruang kurang mengakomodasi perbedaan prestasi kerja, tingkat kompetensi, dan kinerja pegawai yang lebih baik. Sistem penilaian kinerja melalui SKP dipandang kurang obyektif, sehingga sangat memungkinkan timbulnya unsur suka dan tidak suka dan bahkan kontra produktif. Lahirnya kebijakan pemberian Tunjangan Pebaikan Penghasilan (TPP) lebih mendapat respon positif dari para ASN dibanding kenaikan gaji pokok. Demikian pula dengan pola penyelenggaraan diklat dengan memberi kesempatan secara adil akan meningkatkan motivasi pegawai. Walaupun demikian, kesempatan yang dimiliki oleh ASN untuk mengikuti diklat masih sangat terbatas. Hal ini tercermin dari hasil kajian dokumen Dinas Pekerjaan Umum dan Penataan Ruang Kabupaten Barru yang hanya menganggarkan kurang dari 5\% dari total belanja pada tahun 2019.

Secara tidak langsung, kompensasi dan diklat berpengaruh positif dan signifikan terhadap motivasi kerja melalui pengembangan karir. Kesimpulan ini didukung oleh hasil penelitian Hastomo (2009), dengan kesimpulan bahwa terdapat hubungan yang positif dan signifikan antara pelaksanaan pengembangan karir terhadap motivasi kerja karyawan. Seorang ASN senantiasa termotivasi untuk menunjukkan kinerja terbaiknya dengan harapan akan memperoleh promosi jabatan. Ketika mendapatkan promosi 
jabatan tentunya akan memperoleh kompensasi yang lebih baik lagi karena diikuti dengan kenaikan gaji, tunjangan, insentif, dan fasilitas lainnya. Berdasarkan hasil penelitian ini pula bahwa pengaruh diklat terhadap motivasi kerja cukup besar. Oleh karena itu diperlukan adanya koordinasi yang baik antara unit kerja dengan bagian kepegawaian untuk melihat kebutuhan diklat. Hal ini sangat penting mengingat tidak semua kebutuhan diklat dapat dilakukan sendiri oleh Organisasi Perangkat Daerah. Demikian pula dengan Organisasi Perangkat Daerah itu sendiri haruslah cermat melihat kebutuhan diklatnya, dan yang lebih penting adalah memberikan kesempatan yang sama kepada pegawainya. Dengan memberikan kesempatan yang sama kepada pegawai untuk mengikuti diklat akan meningkatkan motivasi dalam rangka pembinaan kompetensi. Dengan diklat yang cukup, seorang ASN akan termotivasi dalam bekerja sehingga kesempatan untuk mengembangkan karirnya sangat terbuka.

\section{SIMPULAN, SARAN, dan KELEMAHAN PENELITIAN Simpulan}

Berdasarkan hasil penelitian dapat disimpulkan bahwa 1) kompensasi dan diklat secara langsung berpengaruh positif dan signifikan terhadap pengembangan karir ASN Dinas Pekerjaan Umum dan Penataan Ruang Kabupaten Barru; 2) kompensasi dan diklat secara langsung berpengaruh positif dan signifikan terhadap motivasi kerja ASN Dinas Pekerjaan Umum dan Penataan Ruang Kabupaten Barru; dan 3) kompensasi dan diklat berpengaruh positif dan signifikan terhadap motivasi kerja melalui pengembangan karir ASN Dinas Pekerjaan Umum dan Penataan Ruang Kabupaten Barru.

\section{Saran}

Disarankan kepada pimpinan unit kerja agar senantiasa memotivasi ASN dalam rangka peningkatan kinerja. Pemberian kompensasi terutama Tunjangan Perbaikan Penghasilan agar dilakukan dengan sistem yang yang jelas sehingga kompensasi yang diterima telah sesuai dengan kinerja masing-masing. Pengembangan karir hendaknya dilaksanakan secara terbuka dan memberikan kesempatan yang sama kepada setiap pegawai.

\section{Kelemahan Penelitian}

Bisa terjadi variabel kompensasi dipengaruhi oleh variabel pengembangan karir. Untuk hal tersebut, dapat menjadi topik bagi peneliti selanjutnya Demikian pula komponen pelatihan dan studi lanjut yang terdapat pada variabel pengembangan karir dapat menjadi salah satu bahan untuk diubah dengan komponen lain pada penelitian selanjutnya.

\section{DAFTAR PUSTAKA}

Aziz, Nofriandi. 2014. Pengaruh Kepemimpinan dan Kompetensi terhadap Kinerja Karyawan PDAM Kota Padang. Serang: Fakultas Ekonomi dan Ilmu sosial Vol.1 Universitas Serang Raya.

Dessler, Gary. 2009. Manajemen Personalia.Jakarta: Erlangga.

Hayani dkk, 2012. Pengaruh Kompensasi Terhadap Motivasi Kerja dan Kinerja (Studi Pada Karyawan PT.Telekomunikasi Indonesia, Tbk Malang). Jurnal $\begin{array}{llllll}\text { Administrasi } & \text { Bisnis } & \text { (JAB) } & \text { Vo.25 } & \text { Np.1 } & \text { Agustus }\end{array}$ 
administrasibisnis.studentjournal.ub.ac.id.https://media.neliti.com/media/publica tions/86156-ID-pengaruh kompensasi-terhadap-motivasi-ke.pdf

Mangkunegara, Anwar Prabu. 2010. Manajemen Sumber Daya Manusia, Bandung: PT. Remaja Rosdakarya

Rahman, dkk. 2014. Pengaruh Kompensasi dan Kepemimpinan Terhadap Kinerja karyawan Dengan Motivasi Sebagai Variabel Intervening (Studi Kasus Pada karyawan Bagian Pabrik PT. JEMBER INDONESIA). Jember : Fakultas Ekonomi Universitas Jember.

Rivai, Veithzal. 2010. Manajemen Sumber Daya Manusia Untuk Perusahaan Dari Teori ke Praktik. Jakarta: Raja Grafindo Persada.

Simamora, Henry. 2009. Manajemen Sumber Daya Manusia. Yogyakarta: STIE YKPN. Singarimbun, Masri dan Sofian Effendi, Metode Penelitian Survei, 2008. Jakarta: LP3ES.

Sofyandi, Herman. 2008. Manajemen Sumber Daya Manusia. Yogyakarta: Graha Ilmu.

Tri Hastomo, Yogi Java, 2009. Hubungan Pelaksanaan Pengembangan Karir Terhadap Motivasi Kerja Karyawan Departemen Human Resource PT Panasonic Shikoku Electronic, Batam.

Undang-Undang Nomor 5 Tahun 2014 tentang Aparatur Sipil Negara

Wibowo, 2012. Manajemen Kinerja, Jakarta: PT. Raja Grafindo Parsada. 